'llu. Revista de Ciencias de las Religiones

ISSN: $1135-4712$

http://dx.doi.org/10.5209/ILUR.53851

\title{
Ateísmo y espiritualidad
}

Alicia Ramos González ${ }^{1}$

Recibido: 13 de abril de 2016 / Aceptado: 16 de junio de 2016

Resumen. El artículo presenta un acercamiento a la nueva espiritualidad. Dentro del mundo contemporáneo cada vez es más frecuente encontrar personas ateas y espirituales. ¿En qué coordenadas ideológicas es esto posible?, intentaremos abordarlo. En primer lugar se esboza un acercamiento en torno al concepto de religión y se presenta una perspectiva histórica de los avatares del término en el siglo XX. Entendemos que hay una dependencia directa entre la definición de religión y la posibilidad o no, de una religiosidad atea. Por otro lado, analizamos, como ejemplo del contexto del siglo XX, la previsión freudiana en torno al fin de las religiones y plantemos las posibles causas de su fracaso.

Palabras clave: Ateísmo; teísmo; espiritualidad; materialismo; Dios.

\section{[en] Atheism and spirituality}

\begin{abstract}
In this article we present an approach to the new spirituality. In contemporary world we find atheistic and spiritual people. How is this possible? We try to analyze. First we make an approach to the concept of religion. We present a historical perspective of the concept. An atheistic religion is possible depending on the definition of religion we use. Also we analyze, as an example of the context of the twentieth century, Sigmund Freud forecast around the end of religions and analyze the causes of failure. Keywords: Atheism; theism; spirituality; materialism; God.
\end{abstract}

Sumario. 1. Introducción. 2. El concepto de religión. 3. La nueva espiritualidad. 4. La tensión entre teísmo y ateísmo. 5. Freud y el fin de las religiones. 6. La espiritualidad sin Dios. 7. Conclusiones. 8. Bibliografía.

Cómo citar: Ramos González, A. (2016), Ateísmo y espiritualidad, en 'Ilu. Revista de Ciencias de las Religiones 21, 165-183.

\section{Introducción}

En nuestra sociedad contemporánea cada vez resulta más frecuente encontrar a personas que se consideran ateas y espirituales. Pretendemos esbozar las coordenadas ideológicas y sociales en las que esto se hace posible. Tras elaborar un breve análisis del concepto de religión, planteamos la cuestión básica: ¿Es posible una religión sin Dios? Entendemos que existe una dependencia directa entre la definición de religión y la posibilidad o no de una religiosidad atea.

\footnotetext{
$1 \quad$ Universidad de Sevilla (España).

E-mail: alikiramos@hotmail.com
} 
A pesar de las fallidas predicciones del fin de las religiones (frente al auge de la cosmovisión científica), nuevas religiones y una nueva espiritualidad se abren paso. Muchas personas abogan por autodenominarse espirituales y no religiosas, o incluso ateas. Ello no implica para nada la desaparición de una espiritualidad interior o individual, ni la posibilidad de vivir experiencias místicas o transcendentales. A este fenómeno es al que deseamos acercarnos en este artículo. Lo haremos presentando brevemente algunas sistematizaciones (la nueva espiritualidad o la espiritualidad sin Dios), ahondando en la tensión entre teísmo y ateísmo, y presentando algunas de las posibles causas del fracaso del predicho fin de las religiones.

Las cuestiones se suceden: ¿Asistimos a una modificación del concepto de Dios? ¿Podemos denominar religiosas a este tipo de experiencias? Son numerosas las denominaciones propuestas para abordar este fenómeno: espiritualidad secular, secularidad sagrada, agnosticismo místico, etc. Los trabajos de A. Comte-Sponville ${ }^{2}$ y de S. Freud ${ }^{3}$ nos servirán de punto de partida para realizar el presente análisis.

\section{El concepto de religión}

Muchos de los nuevos movimientos religiosos ${ }^{4}$ se autodenominan ateos y no religiosos. En cambio sí se consideran espirituales. En la mayoría de los casos se trata de una cuestión conceptual: se identifica religión con teísmo. La cuestión básica consiste en la siguiente: ¿es posible una religión sin Dios? La respuesta reside en el concepto de religión, es decir en cómo definamos religión.

Por un lado encontramos la toma de conciencia del carácter histórico del término religión y de su dependencia lingüística cultural. Desde este punto de vista, existe toda una corriente de definiciones de religión, que abogan por el concepto de Dios como el pilar básico componente de una religión. Esta es la tendencia del Diccionario Akal de las religiones, por ejemplo. En la definición de religión que se esboza en el mismo se especifica:

En la perspectiva que aquí se adopta, religión, es una categoría interpretativa, con una historia propia que forma parte de la historia de la cultura occidental y de la tradición religiosa judeocristiana que la caracteriza ${ }^{5}$.

Los términos dios y religión tienen una raíz geográfico-lingüística y cultural concreta, y su utilización allende las fronteras de la realidad en la que se acuñó resulta

\footnotetext{
Comte-Sponville 2008

Freud 2012.

$4 \quad$ Nos referimos a grupos de corte neobudista, neovendanta, o a los influenciados por las psicoterapias. Seguimos la sistematización de Lynda Woodhead sobre los nuevos movimientos religiosos. Resumiendo brevemente, distingue tres tipologías: por un lado mind-body-spirit (grupos centrados en el bienestar; equilibrio mental, físico y espiritual). La influencia de las psicoterapias es muy marcada en ellos. Por otro lado New Age (grupos que tienen en común la creencia en un camino de progresión de la humanidad que se está concretando en el surgimiento de una nueva era). Existe toda una corriente oriental dentro de la Nueva Era en la que se insertan neobudismo y neohinduismo. Y finalmente el paganismo (grupos centrados en retomar los ideales románticos de los orígenes, en la búsqueda de los dioses y diosas precristianos, tanto de Europa como de la antigua América- neochamanismo-). Se recomienda consultar Woodhead 2005.
}

5 Filoramo 2001, 477. 
etnocentrista ${ }^{6}$. Se ha visto incluso como un gesto de violencia cultural. Ni siquiera la etimología está clara (religere, religare) ${ }^{7}$.

Por otro lado deberíamos de tener en cuenta las diferencias entre los hechos identificados como religiosos y la gran variedad de palabras (incluso pertenecientes a campos semánticos distintos) con las que los sujetos que protagonizan esos hechos se identifican a sí mismos.

No obstante, existe la posibilidad de aportar una definición amplia de religión, una que alberge otras realidades religiosas como son por ejemplo el budismo y el jainismo, ambas caracterizadas por el ateísmo, ambas religiones sin Dios personal. Es posible, si entendemos religión de forma abierta, como cierto anhelo de transcendencia. En este sentido, apunta Agustín Pániker:

Tiene que ver con la relación entre los humanos y una realidad que los trasciende. Todas las religiones remiten a un nivel de la realidad más profundo ${ }^{8}$.

Aunque hay que tener en cuenta que trascender el mundo no es sólo salir del mundo para unirse con algo superior o externo a él, sino que puede ser también entrar en el mundo, vivir lo Verdadero, vivir de Verdad. Incluso podríamos dejar de lado la palabra trascender y hablar por ejemplo de un nivel profundo de realidad.

También podríamos citar algunas otras definiciones en esta línea. Jonh Bowker en el Diccionario abreviado Oxford de las religiones ${ }^{9}$ dedica un epígrafe introductorio a la problemática del término religión. Del mismo hemos extraído dos definiciones que nos resultan interesantes. La primera es de R.N. Bellah ${ }^{10}$ y la segunda de Peter Berger $^{11}$.

Una definición breve y asequible de la religión resulta bastante más difícil que una definición de la evolución. Así que permítanme definir la religión como un conjunto de formas y actos simbólicos que relacionan al hombre con las condiciones esenciales de la existencia ${ }^{12}$.

La religión es la actitud humana hacia un orden sagrado que abarca, en el interior de todos los seres -tanto humanos como no humanos-, una creencia en un cosmos, cuyo sentido incluye y transciende a la vez al ser humano ${ }^{13}$.

Hay, no obstante, otra característica del término religión que no debemos obviar y es la tensión dogma/práctica. Cada vez, con más frecuencia en Europa grupos de musulmanes y judíos reniegan del término religión y prefieren ser entendidos como estilos o formas de vida. Argumentan que si religión es sinónimo de fe, de creencia íntima, ellos y ellas son algo más que eso. Son una forma de vida, pues la religión ordena sus vidas (divide las partes del día, establece una determinada alimentación,

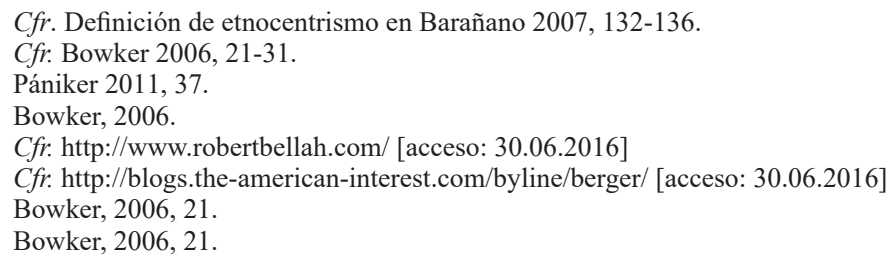


higiene, relaciones sexuales, ética, etc.) Si ahondamos un poco más nos daremos cuenta de que sólo los grupos cristianos se autodenominan como religión y estos mismos, en su esfuerzo por comprender otras culturas han hecho uso del término para referirse a lo que han considerado como tal de las otras culturas.

Las cuestiones se multiplican ¿cuáles son los elementos constituyentes de la religión? ¿Podemos hablar de religión en singular o de religiones en plural? ¿En qué consiste el hecho religioso? ¿Es una religión una ideología o una práctica, o ambas cosas? ¿Es el ser humano religioso o espiritual por naturaleza?

No creemos en la posibilidad de una respuesta consensuada a todas estas cuestiones. Nuestra visión del mundo es siempre parcial y tiene un punto de partida lingüístico cultural. Como apuntaba Wittgestein en el Tractatus logico-philsophicus 5.6: "los límites de mi lenguaje significan los límites de mi mundo".

Esta parcialidad humana para abordar el entendimiento del mundo, nos remite al círculo hermenéutico inevitablemente. Es necesaria una precomprensión de lo que es religión para identificar los fenómenos religiosos y esa precromprensión es producto de factores como la propia tradición, el lenguaje ordinario, datos históricos, etc.

Sin un concepto de religión, de alguna manera apriorísitico, resulta imposible determinar cuáles son aquellos fenómenos a los cabe dar el calificativo de religiosos ${ }^{14}$.

Tampoco es éste el momento de indagar mucho más en estas cuestiones. Lo que nos proponemos es realizar un acercamiento a la relación entre ateísmo y espiritualidad, y no tanto un ahondamiento en el concepto de religión que puede resultar inabarcable.

\section{La nueva espiritualidad}

Cuando nos acercamos al estudio de los nuevos movimientos religiosos pronto percibimos la tensión problemática del concepto religión. Tienden a denominarse espirituales y no religiosos. Por ejemplo, muchos grupos se denominan Sociedades o Asociaciones y rehúyen así del término religión (Sociedad Teosófica ${ }^{15}$, Sociedad Internacional para la Conciencia de Krishna ${ }^{16}$, Asociación Zen Taisen Deshimaru ${ }^{17}$, etc.).

La problemática en torno al concepto religión es tan sólo una de las causas, también lo es el descrédito de las religiones institucionalizadas entendidas como organismos de poder, asfixiantes o incluso corruptos.

Para muchos religión es sinónimo de religión oficial institucionalizada (con toda la parafernalia que comporta la asociación) y espiritualidad está libre de esas connotaciones y se constituye como una actitud o un núcleo subjetivo experiencial (y, con frecuencia, allende la religión) ${ }^{18}$.

\footnotetext{
Duch 2001, 99.

http://sociedadteosofica.es/ [acceso: 30.06.2016].

http://www.iskcon.org/[acceso: 30.06.2016].

http://zenkan.com/[acceso: 30.06.2016].

Pániker 2011, 31.
} 
El descrédito de los religioso que vimos que propiciaba la modernidad ha llevado a que algunos grupos rehúyan el calificativo de religión y prefieran otras denominaciones (espiritualidad, fe $)^{19}$.

De esta forma, la nueva espiritualidad se configura como una forma de relacionarse con lo Transcendente más personal, a veces, incluso caracterizada en muchos casos por la ausencia de un Dios personal.

Tradicionalmente el término espiritualidad hacía referencia a corrientes místicas dentro de las religiones tradicionales. A partir del siglo XIX se estableció una diferencia entre religión (más centrada en el dogma) y espiritualidad (más centrada en la experiencia personal). No debemos obviar la influencia que el romanticismo y el protestantismo tuvieron en ello.

Mucho se ha discutido sobre cómo denominar a las nuevas comunidades religiosas: nuevos movimientos religiosos, sectas, nuevas religiones, nueva espiritualidad. El término secta posee un innegable carácter peyorativo, su uso resulta subjetivo y valorativo.

Secta es en la actualidad (en nuestro país de modo claro) un término de carácter netamente peyorativo y por ejemplo el calificativo roza el límite del insulto. Resulta además extremadamente religiocéntrico puesto que suele aplicarse por parte de las religiones mayoritarias a grupos minoritarios para marcar su marginalización o también, por parte de ciertas minorías, a las iglesias mayoritarias o a colectivos dentro de las mimas, como insulto (calificar de secta al catolicismo, al Opus Dei o plantear que la estructura vaticana es la de una secta $)^{20}$.

En cuanto a "nuevos movimientos religiosos" mucho se ha objetado al respecto del uso de nuevo, pues es algo que depende siempre del contexto. Hay que tener en cuenta que religiones como Hare Krishna o el Budismo de la Tierra Pura no son nuevas en oriente, su proyección histórica es más bien dilatada. Pero en Europa y América resultan novedosas o alternativas. Por otro lado religiones como el espiritismo o la Iglesia de los Santos de los Últimos Días (fundada en 1830) cuentan ya con casi doscientos años. Allan Kardec publicó El Libro de los Espíritus en 1857. La Sociedad Teosófica se fundó en 1875. ¿Cuánto tiempo ha de pasar para que un movimiento o grupo religioso pase de ser nuevo a tradicional? También cabe preguntarse si a todo movimiento religioso, por el mero hecho de haber surgido en el siglo XX, se le puede denominar nuevo. Quizás sea necesario que el corpus de creencias de estos grupos presente la imprenta del mundo contemporáneo y por ello diferencias con las religiones tradicionales.

Hay que tener en cuenta que para caracterizar como nueva religión a un grupo religioso [...] es necesario que la estructura de creencias haya mutado en algún grado como resultado del impacto con la modernidad y que presente rasgos diferenciales respecto de las religiones tradicionales ${ }^{21}$.

\footnotetext{
9 Díez de Velasco 2000, 23.

Díez de Velasco 2000, 16.

Díez de Velasco 2000, 34.
} 
También se critica, por otro lado, el uso de movimiento, como una forma de discriminación frente a religión ${ }^{22}$. No obstante, estos grupos en su estructura interna rehúyen de la fuerte institucionalización y funcionan como sociedades, asociaciones o incluso redes sociales.

En cuanto a la denominación "nuevas religiones" se argumenta que es menos peyorativa y más equitativa.

Nuevas religiones es un término de carácter más neutral, que no caracteriza de modo diferente a priori el objeto de estudio: serían religiones en la misma medida que lo son tanto las denominadas grandes religiones como las que conocemos por la etnografía o las que han desaparecido, pero de las que se dispone de documentación para su estudio. Al no presentar connotaciones peyorativas y reflejar no una diferencia sustancial sino el ámbito diferente que ilustra el adjetivo, será el término que empleemos ${ }^{23}$.

No obstante debemos de tener en cuenta que la mayor parte de las personas que pertenecen a estas comunidades no se consideran a sí mismas religiosas y que, como ya hemos comentado, cuando se registran legalmente lo hacen bajo la denominación de sociedades, asociaciones, centros, comunidades, fraternidades, escuelas, etc.

En los países abiertos a la laicidad (es en estos países en donde existen nuevos movimientos religiosos o espirituales) vemos, como desde un punto de vista individual, muchas personas abogan por autodenominarse espirituales y no religiosas o incluso ateas. No obstante esto no implica para ellas la desaparición de la espiritualidad e incluso la posibilidad de vivir experiencias místicas y esto es lo que nos interesa para este acercamiento.

En esta línea de pensamiento encontramos por ejemplo a pensadores como André Comte-Sponville, Agustín Pániker y también, yéndonos más atrás en el tiempo a Sigmund Freud.

\section{La tensión entre teísmo y ateísmo}

Comte-Sponville considera la existencia de religiones ateas o agnósticas como el budismo, el confucionismo y el taoísmo ("Todo teísmo es religioso, pero no toda religión es teísta" ${ }^{24}$ ), no obstante propondrá una definición del concepto de religión en la que son necesarios los dioses o Dios.

Llamo religión a todo un conjunto organizado de creencias y de ritos referidos a cosas sagradas, sobrenaturales o trascendentes (en el sentido amplio de la palabra), y especialmente a uno o varios dioses (en el sentido restringido), creencias y ritos que reúnen en una misma comunidad moral y espiritual a quienes se reconocen en ellos o los practican ${ }^{25}$.

\footnotetext{
Cfr. Díez de Velasco 2000, 16.

Díez de Velasco 2000, 17.

Comte-Sponville 2008, 21.

Comte-Sponville 2008, 22.
} 
Es necesario apuntar que el concepto de Dios, ya que se parte desde un punto de vista judeocristiano, es el de un Dios personal.

Entiendo por Dios un ser eterno, espiritual y trascendente (a la vez exterior y superior a la naturaleza) que habría creado consciente y voluntariamente el universo. Se le considera perfecto y bienaventurado, omnisciente y omnipotente. Es el Ser supremo, creador e increado (es causa de sí mismo), infinitamente bueno y justo, del que todo depende y que no depende de nada. Es el absoluto en acto y en persona ${ }^{26}$.

Las religiones, si las identificamos con el teísmo de origen abrahámico, aportan el más allá (fin de los tiempos, Origen, etc.) como solución al problema de la muerte (aunque existe mucha elaboración teológica en torno al problema de la muerte y la cuestión no es tan simple). No obstante, bajo este sesgo las religiones pueden ser entendidas como esperanza en el porvenir.

En cambio el ateísmo no espera al mañana y se impone como acción centrada en la vida aquí y ahora.

Los ateos no tienen esas preocupaciones, se aceptan como mortales, en la medida de lo posible, y se esfuerzan por acostumbrarse a la nada [...] La muerte se llevará todo, incluso las mismas angustias que inspira. La vida terrestre importa más, y les basta ${ }^{27}$.

No debe identificarse materialismo con ateísmo. El materialismo racionalista ${ }^{28}$ se centra en la relación mente/cerebro y no podemos encontrarlo, al menos en los mismos términos, en las religiones orientales ateas. Esto no quiere decir que un determinado tipo de ateísmo no tenga como consecuencia coherente al materialismo. Comte-Sponville de hecho se considera a sí mismo un ateo materialista. En general, en occidente esta será una opción corriente, puesto que el auge de la neurociencia tiende a imponer un materialismo en el que no cabe Dios o el alma, en el que todo reside en el cerebro.

Es el caso, por ejemplo, de Kia Nobre ${ }^{29}$, neurocientífica de la Universidad de Oxford, que desde el campo de la neurociencia cognitiva postula que la percepción de la realidad y del tiempo reside en el cerebro. Es nuestro cerebro el que ha "creado" el tiempo para organizar en él nuestra experiencia. Lo que vemos del mundo responde a nuestras expectativas y predicciones. Es una proyección de las posibilidades esperadas. La memoria es un conjunto de acontecimientos que hemos escogido. Los recuerdos cambian constantemente la forma en la que percibimos el mundo y permiten optimizar los comportamientos. En el cerebro está toda la realidad, nuestra realidad.

Determinadas cuestiones a las que la ciencia ha dado respuesta han reforzado el ateísmo en muchas personas del ámbito occidental.

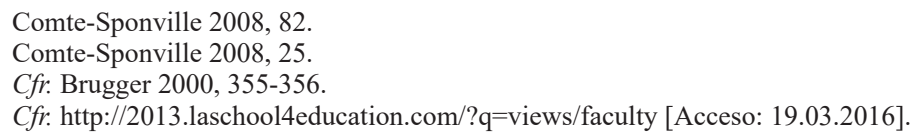


Si el azar (de las mutaciones) crea orden (mediante la selección natural), ya no se necesita de un Dios para explicar la aparición del hombre. La naturaleza es suficiente ${ }^{30}$.

Este punto de vista tendrá interesantes aplicaciones en el seno de muchos de los nuevos movimientos religiosos. Por ejemplo la idea de que la naturaleza es suficiente se verá expresada en la Hipótesis Gaia $^{31}$, que presenta a nuestro planeta como un superorganismo que se autorregula a sí mismo. Esta hipótesis prescinde de la idea de Dios y entronca mucho mejor con los principios de la ecología.

Nosotros no hicimos el mundo ni el mundo fue hecho para nosotros. ¿Por qué habría de adecuarse totalmente a nuestros deseos, nuestras necesidades y nuestras exigencias? $?^{32}$.

Estas ideas suponen una cura de humildad para la especie humana. A su luz muchas personas se sienten menos hijas de Dios y más hijas de la tierra o de la naturaleza (este sentimiento impregna algunas nuevas religiones como por ejemplo la wicca $^{33}$ o los grupos de biodanza ${ }^{34}$ ). La vida de las demás especies del planeta tiene el mismo valor que la vida de nuestra propia especie. Surge así el respeto por los derechos de los animales (a veces reflejado en ciertas legislaciones sobre protección animal, sobre todo referidas a animales domésticos, con multas y penas por maltrato animal; también se desarrolla una ética en torno a la forma de sacrificar los animales para el consumo humano reflejada en España en la Ley 32/2007, de 7 de noviembre, para el cuidado de los animales, en su explotación, transporte, experimentación y sacrificio). Se criticarán por otro lado fiestas populares como las corridas de toros y otras festividades de larga tradición en la que se sacrifican animales.

El respeto a la naturaleza, a la madre tierra tendrá interesantes desarrollos espirituales. Por ejemplo, en cuanto al problema del mal en el mundo, Comte-Sponville nos habla del sufrimiento animal. En la cosmovisión abrahámica, el ser humano está por encima del nicho ecológico, se considera a sí mismo un ser privilegiado, el único con derecho a la salvación, para el que la explotación del medio es un derecho pleno. El sufrimiento animal como fuente de mal en el mundo jamás se hubiese planteado en ella.

¿Qué decir entonces de la invención de los carnívoros? La vida, tal como se supone que Dios la creó, y mucho antes de la aparición del Homo Sapiens, presenta una violencia y una injusticias espantosas. Es como una prolongada carnicería que no tendrá fin $^{35}$.

El considerar al ser humano como un animal cualquiera, que forma parte del medio ambiente sin privilegios sobre él, ha llevado a occidente a una transformación de la sacralización de la humanidad. Ya no es sagrada como hija de Dios, sino

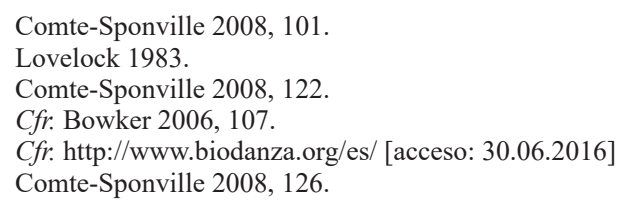


sagrada como hija de la madre tierra, la sacralidad está en los lazos de unión con la naturaleza, lazos que pueden ser o no entendidos como trascendentales. No somos nada extraordinario, no somos hijos de Dios, o creados por Dios. Y aquí de nuevo la hipótesis atea cobra fuerza.

La selección natural puede bastarse para explicar que seamos capaces de amor y de valentía, de inteligencia y de compasión: se trata de otras tantas ventajas selectivas que vuelven más probable la transmisión de nuestros genes. Pero que seamos hasta tal punto capaces de odio, de violencia y de mezquindad, esto (que el darwinismo explica sin dificultad) me parece que excede los recursos explicativos de cualquier teología [...] Creer en Dios es un pecado de orgullo. Sería atribuirse una gran causa para un efecto tan pequeño. El ateísmo, al contrario, es una forma de humildad. Somos hijos de la tierra ${ }^{36}$.

Otra cuestión interesante en torno al ateísmo es la de la posibilidad de una sociedad sin religión (entendiendo religión como teísmo y como estamento social institucionalizado). Las personas que forman parte de una sociedad necesariamente deben de tener lazos de unión. En Europa la creación de los estados modernos siguió un modelo caracterizado por un estado/ una religión. Pero en la Europa contemporánea y con el auge de la laicidad ${ }^{37}$ estos lazos de unión (fe y patria) se han visto un tanto modificados. No creemos que hayan sido sustituidos por otros lazos de unión, simplemente muchas cuestiones han pasado de ser religiosas, o sea cuestiones de fe, a ser éticas o morales. En esta línea Comte-Sponville declarará:

He llegado a definirme como un ateo fiel: ateo, porque no creo en ningún Dios ni en ninguna potencia sobrenatural: pero fiel, porque me reconozco en una determinada historia, una determinada tradición, una determinada comunidad, y especialmente en esos valores judeocristianos (o grecojudeocristianos) que son los nuestros ${ }^{38}$.

Afirmaciones similares son comunes en el panorama actual español.

Como bien apunta Comte-Sponville:

La pérdida de la fe no altera para nada el conocimiento [...] Tampoco afecta en nada, o casi nada, a la moral. ¡No por haber perdido la fe vais de pronto a traicionar a vuestros amigos, robar o violar, asesinar o torturar! $!^{39}$.

Para las personas ateas, en general, la moral es muy relevante.

Lo que confiere valor a una vida humana no es el hecho de que la persona en cuestión crea o no en Dios o en una vida después de la muerte [...] ¡lo que da valor a una vida humana no es la fe, tampoco la esperanza, sino la cantidad de amor, de compasión y de justicia de que somos capaces! ${ }^{40}$.

\footnotetext{
Comte-Sponville 2008, 132.

Cfr. Bobbio 1983, 856-860.

Comte-Sponville 2008, 46.

Comte-Sponville 2008, 56.

Comte-Sponville 2008, 71.
} 
En realidad, no es la religión la que funda la moral, sino que nos parece que la ética o moral es algo que la precede, que forma parte de la época y la sociedad en la que surge y que tiende a perpetuarse en la religión. Visto desde el punto de vista histórico queda muy claro. Las religiones surgen inmersas en una sociedad histórica y esta sociedad no está vacía y es llenada por la religión. La religión no surge como algo distinto de ella. En muchos casos las religiones suponen la culminación coherente de una serie de ideas presentes en una determinada época. La justicia que estipula los derechos y los deberes de las personas que componen una sociedad, que se basa en dar a cada individuo lo que le corresponde, es anterior a una determinada religión (entiéndase aquí religión como sociedad religiosa). Todas las sociedades humanas han compartido unos determinados valores, una serie de deberes, una ética común. El Diccionario Akal de filosofía ${ }^{41}$ define moral como:

Sistema público informal que se aplica a todas las personas racionales, gobierna su conducta cuando afecta a otros, tiene como finalidad la disminución del mal o del daño e incluye lo que normalmente se conoce como reglas morales, ideales morales y virtudes morales ${ }^{42}$.

Las sociedades humanas se configuran en torno a lazos de comunión y uno de ellos es la ética. La idea de que las religiones surgen en un determinado momento histórico y forman parte de la moral de la época o lugar puede apreciarse más claramente si abordamos los nuevos movimientos religiosos. Todos ellos están impregnados de una moral global expresada en la Declaración Universal de los Derechos Humanos y de la visión del mundo científica. Afrontan los problemas actuales, se posicionan ante ellos, aportan soluciones y respuestas a las principales cuestiones de la contemporaneidad. Es normal que estén influenciados por el momento y la sociedad de la que forman parte. Se insertan en la moral de hoy en día. Otra cosa es que se posicionen de forma crítica ante aspectos de esta sociedad, como muy probablemente hacen otras muchas personas adscritas a corrientes religiosas o no. Ponemos por ejemplo el caso del veganismo. Donald Watson y Elsie Shrigley fundaron la Vegan Society $^{43}$ en 1944. Definirán al veganismo como una forma de vida basada en el rechazo a las formas de explotación y de crueldad animal basándose en la compresión de que los animales son seres sensibles. La práctica consiste en el vegetarianismo estricto, basado en no consumir nada que tenga origen animal (huevos, lácteos, etc.) y se extiende más allá para conformar todo un estilo de vida. Es una moral que se expresa en la negación a usar tejidos de origen animal, productos probados con animales, en estar en contra de la compra-venta de animales, etc.

El veganismo no se adscribe a ninguna religión, pero muchos de los denominados nuevos movimientos religiosos optarán por él (sobre todo por su relación con la ahimsa ${ }^{44}$ será practicado por personas pertenecientes a grupos neobudistas o neohunduistas). A lo que apuntamos es a que el veganismo como opción ética o moral está presente en nuestra sociedad y puede llegar a perpetuarse a través de un grupo religioso o espiritual, pero no es exclusivo de él.

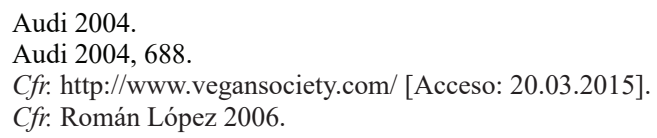




\section{Freud y el fin de las religiones}

Este ateísmo que estamos analizando, entendido como increencia en un Dios personal y enmarcado geográficamente en Europa y América no es nuevo. Ya desde finales del siglo XIX y paralelamente al establecimiento de la cosmovisión científica, se venían realizando críticas a la religión y al concepto de Dios.

En 1927 Sigmund Freud publicó su trabajo Die Zunkunft einer Illusion, publicado en castellano como El Porvenir de una Ilusión. En él se resumen y se ven reflejadas buena parte de estas inquietudes. El psicólogo se posiciona entre los pensadores de la corriente evolucionista. Concibe que el politeísmo (que tiene en su origen a la humanización de la naturaleza) es anterior al monoteísmo (conclusión más coherente). Pero va más allá, cada uno de estos momentos en la historia religiosa de la humanidad se corresponde con una etapa de madurez del ser humano. Más tarde o más temprano, predice, las personas abandonarán la influencia de la religión ante las evidencias del espíritu científico.

Conforme a esta teoría hemos de suponer que el abandono de la religión se cumplirá con toda la inexorable fatalidad de un proceso de crecimiento y que en la actualidad nos encontramos ya dentro de esta fase de evolución ${ }^{45}$.

Así es como percibía su época Freud, pero no sólo él, la desaparición de las religiones fue una predicción muy popular.

Cuando el padre del psicoanálisis indaga sobre los orígenes sociales de nuestra especie, concibe que en el estado de la naturaleza en el que vivían los primeros humanos, la misma naturaleza constituyera una amenaza por lo terrible de sus manifestaciones. Ante la percepción de tal amenaza, los humanos se unieron formando las civilizaciones. Al formar parte de esta unión se vieron obligados a asumir una serie de daños (privaciones impuestas por la sociedad). Esto explica para Freud la existencia de un cierto grado de hostilidad contra la cultura en todas las civilizaciones. Las ideas religiosas asumen así la función de compensar a las personas por las privaciones que la vida social les ha impuesto y a los preceptos morales se les otorga un origen divino. Por otro lado las ideas religiosas tienen además otras funciones: la de espantar los terrores de la naturaleza (función primaria muy presente, según Freud, en las religiones primitivas) y la de conciliar al ser humano con la muerte y su destino.

Esta visión que a nosotros nos parece simplista tuvo suma relevancia en la época y aún hoy tiene cierta vigencia. Nos parece bastante discutible la existencia de un estado de naturaleza anterior al estado social, como un paso previo a la creación de las sociedades. El estado natural del ser humano es el estado social. También la concepción de la naturaleza que presenta resulta ser muy negativa: el entorno natural como una amenaza a las vidas humanas. Parece que los humanos no pertenecen a la naturaleza. Es una visión muy sesgada y más propia de una interpretación judeocristiana. El medio ambiente es hostil a las personas debido al pecado original de Adán y Eva que ha provocado la caída desde el Paraíso. No se trata de una concepción global de la naturaleza, existen muchos tipos de sociedades y la naturaleza puede tener en otras culturas aspectos mucho más positivos ${ }^{46}$.

\footnotetext{
45 Freud 2012, 68.

46 Cfr. por ejemplo Maillard 2001.
} 
Las tres funciones que atribuye a las ideas religiosas son reduccionistas. En primer lugar en cuanto a que espantan los terrores de la naturaleza, ya hemos apuntado que hay sociedades que se conciben a sí mismas como parte de la naturaleza y no perciben ese terror. Sobre la conciliación del ser humano con la muerte, las religiones no suelen dar una clara solución al problema de lo efímero de la existencia, pero aportan consuelo, establecen un proceso de duelo y hacen que las personas se enfrenten a la muerte. Finamente puesto que nos parece que el estado social es el natural a nuestra especie estas "privaciones" que impone la vida en sociedad son naturales y la religión no es la madre de la moral, puede que la perpetúe pero la moral le precede.

En Tótem y Tabú, otro interesante trabajo de Freud, se establece por otra parte que la raíz de la necesidad religiosa está en la búsqueda de una instancia protectora (la nostalgia de un padre). De todas formas no se trataba (siguiendo al mismo autor) de explicar el génesis de la religión sino únicamente del totemismo. Aun así nos ha parecido de relevancia sacarlo a la luz, pues realmente el Dios cristiano tiene mucho de Padre. Esta imagen es etnocentrista pues no todos los Dioses o Entidades Superiores son Padre o Cabeza de familia. Esta idea del Dios Padre nos parece que refuerza el orden social patriarcal de las sociedades occidentales. Así como a los preceptos morales se les atribuirá un origen divino, también al orden social establecido. Lo que no quiere decir que este orden social lo establezca la religión, sino sólo que lo perpetúa.

Esta imagen de la familia que se rige por el modelo patriarcal también la vamos a encontrar reflejada en El Porvenir de una Ilusión. Parece que el psicólogo piensa que este modelo es el orden familiar natural. En muchos casos la ciencia cumple la función de eliminar el origen divino de los órdenes sociales y los perpetúa bajo el orden natural.

De este modo la madre, que satisface el hambre, se constituye como el primer objeto amoroso y, desde luego, en la primera protección contra los peligros que nos amenazan desde el mundo exterior, es la primera protección contra la angustia, podríamos decir. Sin embargo, la madre no tarda en ser sustituida en esta función por el padre, más fuerte, que la conserva ya a través de toda la infancia ${ }^{47}$.

Estas palabras representan un reflejo del modelo social de la Europa de principios de siglo XX. No existe una única sociedad humana, una única civilización humana. Freud resulta etnocentrista en este sentido. Los avances en la antropología han cuestionado con mucha potencia estos modelos y han presentado a la sociedad euro-americana la enorme variedad de tipos de familias y parentescos existentes entre los humanos. No obstante esta interpretación freudiana es interesante por ser ampliamente admitida en la primera mitad del siglo XX. Quizás el cuestionamiento que hará el movimiento feminista del estatus del Padre (reflejado a un nivel Trascendente en la figura del Dios Padre) tenga mucho que ver con la caída parcial del Padre Todopoderoso y el auge de la Madre Naturaleza. Las mujeres tienen un índice muy elevado de participación en los nuevos movimientos religiosos. Y no sólo eso, sino que ocuparán puestos de poder en estos movimientos. Por ejemplo, H. P. Blavastsky

47 Freud 2012, 37. 
además de ser miembro fundador de la Sociedad Teosófica, ocupará un papel muy relevante dentro de la misma; Alice A. Bailey fundó la Escuela Arcana ${ }^{48}$; dentro del mare magnum denominado Nueva Era destacan importantes canalizadoras como Jane Roberts ${ }^{49}$ o Bárbara Marciniak ${ }^{50}$.

Pero siguiendo con Freud, en El porvenir de una ilusión acabará concluyendo que las ideas religiosas son ilusiones. No vienen de la experiencia, ni del pensamiento razonado. Reflejan la esperanza de que los deseos humanos se realicen. "Son ilusiones, realizaciones de los deseos más antiguos, intensos y apremiantes de la Humanidad" 51 . "Calificamos de ilusión una creencia cuando aparece engendrada por el impulso a la satisfacción de un deseo" 52 . "La labor científica es, a nuestro juicio, el único camino que puede llevarnos al conocimiento de la realidad exterior a nosotros"53.

La concepción de que la ciencia tendrá todas las respuestas aún existe, aunque haya quienes han perdido la fe en ello. A lo largo del siglo XX muchas personas han pensado que la ciencia acabaría por sustituir a la religión. Estas predicciones han resultado fallidas ante el enorme auge de las religiones en la última mitad del siglo XX y en lo que llevamos del XXI. "Se calcula que únicamente en los tiempos recientes se han formado unos 40.000 movimientos religiosos". 54

Las nuevas religiones adoptarán un discurso cientificista ${ }^{55}$ y supondrán intentos de aunar religión y ciencia. Las palabras de Freud dedicadas al análisis de su actualidad (recordemos que escribe el libro en 1927) con respecto a la religión son muy reveladoras de la situación de crisis religiosa que vive Europa (que es crisis de la religión cristiana).

Reflexionen sobre la situación actual. Hemos oído la confesión de que la religión no ejerce ya sobre los hombres la misma influencia de antes. (Nos referiremos a la civilización europea cristiana). Y ello no porque prometa menos, sino porque los hombres van dejando de creer en sus promesas. Concedamos que la causa de esta mudanza reside en el robustecimiento del espíritu científico en las capas superiores de la sociedad humana, aunque quizás no sea esta causa la única. La crítica ha debilitado la fuerza probatoria de los documentos religiosos; las ciencias naturales han señalado los errores en ellos contenidos, y la investigación comparativa ha indicado la fatal analogía de las representaciones religiosas por nosotros veneradas con los productos espirituales de pueblos y tiempos primitivos. El espíritu científico crea una actitud particular ante la cosas de este mundo [...] Cuanto más asequibles se hacen al hombre los tesoros del conocimiento, tanto más se difunde su abandono de la fe religiosa, al principio sólo de sus formas más anticuadas y absurdas, pero luego también de sus premisas fundamentales ${ }^{56}$.

48 Cfr. http://www.lucis.org/escuela-arcana/ [acceso:30.06.2016].

49 Jane Roberts (1929-1984) médium estadounidense que recibe una serie de canalizaciones por parte de una entidad denominada Seth. Entre ellas un libro revelado: Cfr. Seth 1972.

50 Bárbara Marciniak. Destacada canalizadora estadounidense, comenzó a recibir en 1987 una serie de mensajes provenientes de unas entidades extraterrenales denominadas Pleyadianos. Cfr. Pleyadianos 2011.

51 Freud 2012, 47.

52 Freud 2012, 49.

53 Freud 2012, 50.

54 Pániker 2011, 62.

${ }_{55}$ Cfr. por ejemplo http://www.scientology.es/ [acceso: 30.06.2016].

56 Freud 2012, 59-60. 
Estas predicciones muy propias de la época, como venimos diciendo, resultaron fallidas por diversas causas. La más importante de ellas es que no contaron con la capacidad de adecuación a las circunstancias que poseen las religiones. Pensaron que eran estamentos y teologías estancas con principios inamovibles. Carecían de la perspectiva histórica que revela los procesos de cambio y adecuación constante por los que han pasado las diversas religiones de larga tradición histórica. Realmente el espíritu científico modificó el modo de ver el mundo. Pero esto no iba a conllevar la desaparición de las religiones, sino la adecuación de las mismas al nuevo discurso dominante. Si las ideas religiosas son una ilusión (creencia engendrada por el deseo y la esperanza humana), lo que ocurre es que las ilusiones cambian con el tiempo y las circunstancias. De todas formas no creemos que la religión sea una ilusión, pero sí que los seres humanos tienen tales ilusiones. No obstante, por último matizar, que esta ilusión de la que habla Freud, podría quizás traducirse en términos religiosos abrahámicos por promesa. Lo que nos lleva a plantearnos la cuestión de si Freud al entender la religión como ilusión está haciendo una interpretación religiocéntrica del término. Aun así destacaremos las palabras finales con las que Freud acaba su trabajo. "No. Nuestra ciencia no es una ilusión. En cambio, sí lo sería creer que podemos obtener en otra parte cualquiera lo que ella no nos pueda dar"s7.

Supone todo un alegato en favor del ateísmo. Una muestra de que las cuestiones que hoy encontramos planteadas en el estudio de Comte-Sponville no son nuevas aunque continúen un poco sin resolver.

\section{La espirtualidad sin dios}

Cambiando de tema y para finalizar es necesario aclarar otra cuestión. Ya que observamos que muchas personas espirituales son ateas ies posible una espiritualidad sin Dios? El ser, a la misma vez una persona atea y espiritual, puede parecer contradictorio a los creyentes. De nuevo la cuestión es puramente conceptual. Para los creyentes cristianos el espíritu o alma es una sustancia inmaterial e inmortal. Es lo divino en lo humano. Pero no siempre inmortalidad y alma van de la mano. Para muchas personas el espíritu es lo que hace posible la autoconciencia y el que sea inmortal o no, tiene muy poca relevancia. El alma es aquello que somos nosotros más allá del cuerpo físico. El concepto deviene del hecho de reconocernos como individuos, es decir, como unidad frente al entorno y frente a los demás, una unidad diferenciada de los otros. La preocupación por el Yo, la autoconciencia subyace en el origen del término alma. Esta concepción del sí mismo es congénita a nuestra especie. Que sea algo inmaterial es una perspectiva, pero existen otras.

La existencia del alma se infiere de la experiencia inmediata que el hombre tiene de sí mismo y de la observación exterior de la vida. No experimentamos, claro está, un alma desligada de sus actos, pero sí vivimos inmediatamente nuestros hechos de conciencia como actividades o estados de nuestro yo, [...] Vivimos la dilatada abundancia de todos los actos simultáneos de conciencia y la corriente

57 Freud 2012, 86. 
cambiante de los sucesivos, como pertenecientes a un mismo y único yo que permanece idéntico en el cambio del acontecer psíquico ${ }^{58}$.

No vivimos el yo como un mero punto de referencia de las actividades, como mero acontecer y devenir, sino como un ser firme en sí mismo (selb-stand) que pone los actos, produce y tiene como suyos los estados psíquicos y es responsable de ellos, en suma, como principio permanente y sustentante de todo vivir anímico consciente ${ }^{59}$.

El materialismo científico presenta al cerebro como órgano entre cuyas funciones está la capacidad de autopercepción, es donde reside la identidad. Ello no tiene por qué invalidar el término de espíritu. Resida donde resida la identidad, el espíritu sigue existiendo. Refiriéndose a ello afirma Comte-Sponville:

Poco importa que esta cosa sea el cerebro, tal como creo, o una sustancia inmaterial, como decía Descartes. No por ello pensamos menos. No queremos menos. No imaginamos menos. ¿Qué es el espíritu? Es la potencia de pensar en tanto que tiene acceso a la verdad, a lo universal o a la risa. Es probable que esta potencia, sin cerebro, fuera impotente e incluso no existiera. Pero el cerebro, sin esta potencia, sólo sería un órgano más ${ }^{60}$.

En este sentido todos somos seres espirituales, autoconscientes, abiertos a la percepción del mundo o de la naturaleza.

Ser ateo no significa negar la existencia del absoluto, sino negar su trascendencia, su espiritualidad, su personalidad; es negar que el absoluto sea Dios. ¡Pero no ser Dios no es ser nada! ${ }^{61}$.

Estas afirmaciones tienen validez dentro del concepto de Dios cristiano. Dios y la Nada, o Dios como Nada están presentes en otras religiones. Existen a nivel mundial diversas tradiciones de elaborada metafísica del Ser caracterizadas por la ausencia del Ser mismo.

Comte-Sponville aporta también una definición de absoluto (en minúscula). Lo absoluto es el conjunto de lo existente, todas las relaciones, todos los puntos de vista, todas las condiciones. Es la naturaleza (cosmos, physis), la totalidad de lo real. Pero no es trascendente o sobrenatural. Partiendo de esta concepción de absoluto elaborará una mística de lo inmanente. En consecuencia se autodefine como materialista.

Ser materialista, en el sentido filosófico del término, equivale a negar la independencia ontológica del espíritu, pero no a negar su existencia (porque entonces el propio materialismo se volverá impensable).

La visión de este pensador es un tanto peculiar y personal, no obstante sus planteamientos son muy actuales y pertinentes, incluso necesarios. ¿Es posible una espi-

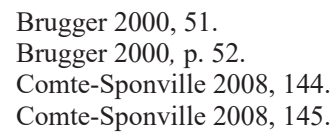


ritualidad sin Dios? Lo estamos viendo en muchos nuevos movimientos religiosos. La cuestión, incidimos, nos parece meramente conceptual. Este ateísmo del que hablamos está presente tan sólo en los continentes europeo y americano. No existe en otras sociedades. Surge ante el descrédito de las religiones institucionalizadas (los cristianismos sobre todo), ante el desmoronamiento de las explicaciones del mundo que aportaba la religión (ante el auge e imposición de la cosmovisión científica) y finalmente deriva de un concepto de religión reducido e identificado con teísmo. También es consecuencia del proceso de secularización, entendido éste como proceso de emancipación de las instituciones religiosas del estado (aunque hay claras diferencias entre el contexto estadounidense - pues Estados Unidos ya nació como una moderna sociedad secular-y Europa) $)^{62}$.

Las nuevas religiones que se denominan no religiosas, ateas y espirituales lo hacen en este contexto que estamos esbozando. No religiosas es una consecuencia de ser ateas (porque una religión se caracteriza por ser la creencia en un Dios, aunque también por estar jerarquizada e institucionalizada).

Necesariamente los términos religión y espiritualidad hacen referencia a realidades distintas y no tienen por qué estar relacionados. Es posible así una espiritualidad sin Dios.

Si todo es inmanente, el espíritu también lo es. Si todo es natural, la espiritualidad también lo es. Esto, lejos de constituir un impedimento para la vida espiritual, es lo que la hace posible. Estamos en el mundo y pertenecemos al mundo: el espíritu forma parte de la naturaleza ${ }^{63}$.

Comte-Sponville va más allá de la espiritualidad sin Dios y esboza la posibilidad de una mística de la inmanencia. ¿Es posible una mística basada en el contacto con la inmensidad de lo existente? ¿Algo más parecido a la experiencia de lo sublime, algo más arcaico en nuestra especie, quizás una característica etológica, una experiencia a la que todas las personas puedan acceder, innata, congénita?

Tenemos una experiencia de lo desconocido (el saber que no sabemos), que forma parte de la espiritualidad (y es lo que yo denomino el misterio). Pero también tenemos, y en primer lugar, y sobre todo, la experiencia de la inmanencia y de la inmensidad [...] Estamos dentro del Todo, y éste, finito o no, nos excede por todas partes: sus límites, si los tiene, se encuentran definitivamente fuera de nuestro alcance. Nos envuelve. Nos contiene. Nos supera. ¿Es una trascendencia? No, porque nosotros nos encontramos dentro. Pero sí una inmanencia inagotable, indefinida, con límites a la vez inciertos e inaccesibles. Estamos en ella: la inmensidad nos lleva en su seno ${ }^{64}$.

Este planteamiento nos resulta interesante. Pero no deja de ser meramente personal, aunque propio y representativo de la época contemporánea. Ser ateo en el sentido de no creer en la existencia de un Dios personal, no impide ser espiritual o estar ciegos al conjunto de seres y acontecimientos que nos rodea.

\footnotetext{
Cfr. Casanova 2008.

Comte-Sponville 2008, 149

Comte-Sponville 2008, 153.
} 
Es el amor, y no la esperanza, el que hace vivir; es la verdad, y no la fe, la que libera. Ya estamos en el Reino de los Cielos: la eternidad es ahora ${ }^{65}$.

\section{Conclusiones}

Para ir concluyendo, creemos que a lo que asistimos es en muchos casos a una modificación radical del concepto de Dios, menos Trascendente y más inmanente, menos Padre y más Naturaleza o Madre Tierra. A veces en movimientos religiosos del estilo Wiccano por ejemplo, aunque no hay una ortodoxia todavía, la naturaleza es la manifestación sagrada de lo Trascendente y lo Trascendente mismo.

Agustín Pániker habla de espiritualidad secular para referirse a esta percepción de lo sagrado en el mundo cotidiano, utopía ecosófica o goce topofílico ${ }^{66}$. Otros lo denominan agnosticismo místico ${ }^{67}$ (Salvador Pániker), secularidad sagrada ${ }^{68}$ (Raimon Panikkar), espiritualidad trans-religiosa ${ }^{69}$ (Vicente Merlo) etc. La cuestión es si podemos denominar religiosas a este tipo de experiencias y la respuesta depende de la definición del concepto de religión por la que optemos. Si definimos religión de forma abierta (yendo más allá del marco geográfico-lingüístico del término) como experiencia de la profundidad de la realidad o de lo transcendente en los humanos, estas serían realmente experiencias religiosas. En cambio si optamos por la definición exclusivista de corte histórico, que entiende a la religión como creencia en un Dios Personal, expresada socialmente en una comunidad de fieles o Iglesia institucionalizada, entonces estas no son experiencias religiosas.

Declara Agustín Pániker:

Soy ateísta. Evidentemente, no lo soy porque sepa que Dios no existe, sino porque no lo necesito. La hipótesis Dios me resulta innecesaria y muchas veces ininteligible. La ciencia puede proveernos hoy de nuevos mitos y de metáforas plausibles. Provisionales, desde luego, y contingentes, pero suficientemente válidas y enriquecedoras ${ }^{70}$.

De nuevo debemos hacer hincapié, en que estos posicionamientos, tienden a ser cada vez más comunes en la sociedad occidental. El concepto de Dios tradicional ha decaído en pos de un Dios (si cabe ponerlo con mayúsculas) más inmanente, más asequible, más visible y cercano, menos Padre, menos Persona y más Naturaleza.

Para mí, Dios es una idea vaga y ambigua, pero no lo es la luminosidad de un día de primavera, el amargo sabor del chocolate, la consciencia de pertenecer a una realidad que todo lo interpenetra ${ }^{71}$.

A pesar de los planteamientos que aquí hemos expuesto al respecto de la espiritualidad sin Dios, hay que tener presente que se trata de un fenómeno parcial, que no

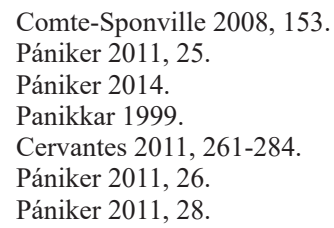


se encuentra en todos los movimientos espirituales de la actualidad. Si bien muchos de ellos hacen frente y aportan soluciones a estas cuestiones, continuará vigente la corriente antimaterialista y teísta. Por ejemplo, grupos de la corriente espiritista se inclinan por un concepto de alma muy vinculado con el tradicional, presente en el cristianismo; el espiritismo reencarnacionista cree en la transmigración de las almas como sustancias inmateriales e inmortales.

Vemos necesaria, no obstante, la indagación en torno al auge de los movimientos y espiritualidades ateístas porque forman parte de nuestro presente más inmediato (y es por ello que hemos realizado este acercamiento).

\section{Bibliografía}

Asociación zen Taisen Deshimaru; http://zenkan.com/[acceso: 30.06.2016].

R. Audi, Diccionario Akal de filosofia. Madrid, Akal, 2004.

A. Barañano et al., Diccionario de relaciones interculturales: Diversidad y Globalización. Madrid, Complutense, 2007.

R. N. Bellah; http://www.robertbellah.com/ [acceso: 30.06.2016].

J. A. Beckford, New religious movements and rapid social change. London, Sage, 1986.

P. Berger; http://blogs.the-american-interest.com/byline/berger/ [acceso: 30.06.2016]

N. Bobbio et al. (dir.), Diccionario de política. México D.F:, SXXI, 1983.

J. Bowker, Diccionario abreviado Oxford de las religiones del mundo. Barcelona, Paidós, 2006.

W. Brugger, Diccionario de filosofía. Barcelona, Herder, 2000.

J. Casanova, "Reconsiderar la secularización: una perspectiva comparada mundial". Revista Académica de Relaciones Internacionales. 7 (2008) 1-20.

C. Cervantes (ed.) Espiritualidad y política. Barcelona, Kairós, 2011.

A. Comte-Sponville, El alma del ateísmo: introducción a una espiritualidad sin Dios. Barcelona, Paidós, 2008.

F. Díez de Velasco, Las nuevas religiones. Madrid, El Orto, 2000.

L. Duch, Armes espirituals i materials. Montserrat, L'Abadía de Montserrat, 2001.

Escuela arcana, http://www.lucis.org/escuela-arcana/ [acceso: 30.06.2016].

Federación espírita española, http://www.espiritismo.es/ [acceso: 27.05.2015].

G. Filoramo, Diccionario Akal de las religiones. Madrid, Akal, 2001.

S. Freud, El porvenir de una ilusión, Madrid, Taurus, 2012.

S. Freud, Tótem y tabú, Madrid, Alianza Editorial, 2011.

W. J. Hanegraff, New Age Religion and Western Culture. New York, Suny, 1998.

P. Heelas, The New Age Movement. Oxford, Blackwell, 1996.

Iglesia de la cienciología; http://www.scientology.es/ [acceso: 30.06.2016].

International biocentric fundation; http://www.biodanza.org/es/ [acceso: 30.06.2016].

J. E. Lovelock, Gaia: una nueva visión de la vida sobre la Tierra. Madrid. Hermann Blume, 1983.

C. Maillard (ed.), El árbol de la vida: la naturaleza en el arte y las tradiciones de la India. Barcelona, Kairós, 2001.

J. Martín Velasco, Introducción a la fenomenología de la religión. Madrid, Trotta, 2006.

J. Martín Velasco, El malestar religioso de nuestra cultura. Madrid, San Pablo, 1997. 
V. Merlo, La llamada (de la) Nueva Era: hacia una espiritualidad místico-esotérica. Barcelona, Kairós, 2007.

A. Pániker, El sueño de Shitala, viaje al mundo de las religiones. Barcelona, Kairós, 2011.

S. Pániker, Sociedad laica y trascendencia. http://www.cetr.net/es/articulos/calidad humana/sociedad_laica_y_trascendencia [acceso: 12.04.2016].

S. Pániker, Diario dē Otoño. Barcelona, Random House, 2014.

R. Panikkar, El mundanal silencio. Barcelona, Martínez Roca, 1999.

Pleyadianos, Mensajeros del Alba: enseñanzas de los pleyadianos. Canalizado por Bárbara Marciniak y editado por Tera Thomas. Barcelona, Obelisco, 2011.

Registro de entidades religiosas del Ministerio de Interior (España). http://maper. mjusticia.gob.es/MAPER/RER [acceso: 17.03.2016].

M. T. Román López, «El concepto de ahimsa en el hinduismo, el budismo y el jainismo». Cuadernos del Marqués de San Adrián: revista de humanidades. 4 (2006) 261-284.

P. Rodríguez Santidrián, Diccionario de las religiones. Madrid, Alianza, 2004.

Seth, Habla Seth, la eterna validez del alma, canalizado por Jane Roberts. Rosario, Eleven-Biblioteca del Nuevo Tiempo, 1972.

Sociedad internacional para la conciencia de Krishna; http://www.iskcon.org/[acceso: 30.06.2016].

Sociedad teosófica; http://sociedadteosofica.es/ [acceso: 30.06.2016].

Sociedad vegana; http://www.vegansociety.com/ [acceso: 13.03.2016].

O. Uña Juárez-A. Hernández Sánchez (directores), Diccionario de sociología. Madrid, Esic, 2004.

L. Wittgenstein, Tractatus Logico-Philosophicus, Madrid, Tecnos, 2007.

L. Woodhead, P. Heelas, et. al. The Spiritual Revolution. Why religion is giving way to spirituality. Chichester, Blackwell Pub., 2005. 